\title{
Elementos constitutivos da história da profissão docente em Montes Claros (1920-1930) ${ }^{1}$
}

\author{
Components of the teaching profession history in \\ Montes Claros/MG (1920-1930) \\ Elementos constitutivos de la historia de la profesión docente en la ciudad de \\ Montes Claros/MG (1920-1930) \\ Elements constitutifs de l'histoire de la profession enseignant a \\ Montes Claros (1920-1930)
}

Geisa Magela Veloso², Mônica Maria Teixeira Amorim³

\section{Resumo}

O artigo objetiva discutir elementos constitutivos da história da profissão docente, nas décadas de 1920-30, partindo da organização da Escola Normal na cidade de Montes Claros, localizada em Minas Gerais/Brasil. O estudo situa-se no âmbito da História Cultural, tomou o jornal Gazeta do Norte como fonte documental e a Revista do Ensino para captar a sincronia do local com discussões propostas em Minas Gerais. No estudo, destaca-se o papel das escolas normais na formação docente, o embate entre formação técnica e cultura geral, a abnegação e a culpa como fundamentos do trabalho docente. Ressalta-se que Montes Claros faz adesão ao programa proposto em Minas, defende o magistério como sacerdócio e o ensino normal como atividade técnica.

Palavras-chave: Profissão docente; História; Escola Normal; Formação docente.

\footnotetext{
${ }^{1}$ A pesquisa contou com apoio financeiro da Fundação de Amparo à Pesquisa do Estado de Minas Gerais (FAPEMIG).

${ }^{2}$ Doutorado em Educação pela Universidade Federal de Minas Gerais. Professora do Programa de PósGraduação em Educação da Universidade Estadual de Montes Claros. E-mail: velosogeisa@ gmail.com

${ }^{3}$ Doutorado em Educação pela Universidade Federal de Minas Gerais. Professora do Programa de PósGraduação em Educação da Universidade Estadual de Montes Claros. E-mail: monicamorimsa@gmail.com
} 


\begin{abstract}
This study aims to discuss the forming elements of the teaching profession history, in the 192030s, based on the organization of the first normal school in the city of Montes Claros, located in the state of Minas Gerais, Brazil. It is placed within the scope of Cultural History, and used the newspaper Gazeta do Norte as documentary source and the magazine Revista do Ensino to capture the local harmony with the proposed discussions in Minas Gerais. The study highlights the role of normal schools for teacher training, the clash between technical training and general education, and self-denial and guilt as fundamentals of teaching. It emphasizes that Montes Claros adheres to the program proposed in Minas, defends teaching as a priestly function and normal education as a technical activity.
\end{abstract}

Keywords: Teaching profession; History; Normal School; Teacher training.

\title{
Resumen
}

El artículo objetiva discutir elementos constitutivos de la historia de la profesión docente en las décadas de 1920-30, partiendo de la organización de la Escola Normal de Montes Claros, ubicada en la provincia de Minas Gerais/Brasil. El estúdio se sitúa en el ámbito de la historia cultural adoptó el periódico Gazeta do Norte como fuente documental y la Revista do Ensino para captar la sincronía local con las discusiones propuestas en Minas Gerais. En el estudio se destaca el papel de las escuelas normales hacia la formación docente, el embate entre la formación técnica y la cultura general, la abnegación y la culpa como fundamentos del trabajo docente. Es importante resaltar que Montes Claros se adhiere al programa propuesto en Minas Gerais, defiende el magisterio (educación formal) como sacerdocio y la formación docente como actividad técnica.

Palabras clave: Profesión docente, Historia, Escola Normal; Formación docente

\section{Résumé}

L'article a pour objectif de discuter des éléments constitutifs de l'histoire de la profession d'enseignant dans les décennies de 1920-1930 à partir de l'organisation de l'Ecole Normale de la ville de Montes Claros, située à Minas Gerais/Brésil. L'étude se place dans le contexte de l'histoire culturelle, comme source documentaire elle utilise le journal Gazeta du Nord ainsi que le Magazine de l'Enseignement afin de capturer la synchronisation de l'endroit avec des discussions proposées à Minas Gerais. Dans cette étude, se distingue le rôle des écoles normales dans la formation des enseignants, l'affrontement entre la formation technique et la culture générale, le renoncement et la culpabilité comme des principes fondamentaux de l'enseignement. Il est à noter que la ville de Montes Claros adhère au programme proposé à Minas Gerais, il défend l'enseignement comme sacerdoce et l'enseignement normal comme activité technique.

Mots-clés: Profession d'enseignant; Histoire; École normale; La formation des enseignants. 


\section{Introdução}

A história da profissão docente no Brasil nos remete à reflexão sobre os anos oitocentos, período em que se intensifica o processo de organização e normatização do exercício dessa profissão no país, e em que emergem as primeiras escolas normais - espaços destinados à formação de profissionais professores. Assim, ao longo do século XIX, a direção da profissão docente no Brasil foi delineada "pelo projeto conservador que a instituiu. Nesse projeto se inseriram as escolas normais, que se encarregariam de definir os saberes e as formas de fazer dos futuros professores". (VILLELA, 2003, p.131, grifos da autora).

A historiografia registra o surgimento das primeiras escolas normais no país no início do século XIX. Dentre as primeiras escolas criadas encontram-se aquelas das províncias do Rio de Janeiro e Minas Gerais, em 1835, da Bahia, em 1836, e de São Paulo, em 1846. Uma significativa produção histórica já se pode encontrar acerca dessas escolas, mas, no caso específico da cidade de Montes Claros, ainda são incipientes os estudos sobre essa instituição, cuja criação remonta ao ano de $1879^{4}$. A análise encaminhada neste artigo objetiva, assim, estabelecer uma aproximação entre o processo de organização da primeira escola normal em Montes Claros, com o cenário mineiro e nacional. Entende-se que a análise da organização das escolas normais lança luzes sobre elementos constitutivos da história da profissão docente em uma realidade particular e traz importantes reflexões para compreender a profissionalização docente - aqui entendida, como assinala Veiga (2001), enquanto processo que envolve a formação de professores e o exercício profissional.

A discussão ora proposta é resultante de investigação situada no âmbito da História Cultural, na perspectiva defendida por Chartier (1990, 2002), que entende a historiografia como possibilidade para se reconstituir o modo como uma determinada realidade social é construída, pensada, dada a ler, em diferentes espaços e tempos. Por essa perspectiva, a história cultural é compreendida como a história das representações - representações que se constituem como matrizes geradoras de discursos e práticas; representações que não são a verdade, mas aquilo que o sujeito pensa que é o real ou aquilo que ele gostaria que fosse.

Deste modo, realizamos pesquisa histórica orientada, não pela crença em acontecimentos verdadeiros, mas pela busca de representações que possibilitassem mapear significações e apropriações produzidas sobre a organização da Escola Normal de Montes Claros e os elementos que, nesse processo, se apresentam como constitutivos da profissão docente. Como fontes documentais, utilizamos o jornal Gazeta do Norte, periódico da cidade de Montes Claros, que circulou entre os anos de 1918 e 1962 e permitiu mapear ocorrências em curso na região Norte Mineira e discutir saberes postos em circulação. Para captar a sincronia do movimento regional com as ocorrências mais amplas, utilizamos a Revista do Ensino/MG publicação oficial do governo de Minas Gerais criada no ano de 1925 com a finalidade de disseminar ideais renovadores e produzir transformações no âmbito das escolas mineiras.

Ao tomar as décadas de 1920 e 1930 como recorte temporal, a opção foi orientada por questões locais, mas referenciada pelas profundas reformas e mudanças produzidas no Brasil, que visavam à reconstrução nacional pela educação, em que o estado de Minas Gerais produziu importantes deslocamentos na sua política educacional. Conforme De Lorenzo e Costa (1997), a década de 1920 é considerada como as origens do Brasil moderno, período em que foram gestadas diversas transformações postas em curso na década subseqüente. Estudos de Maciel e Frade (2006) apontam a década de 1920 como período marcado por uma grande agitação social, econômica e intelectual, em que o Brasil experimenta diferentes manifestações políticoculturais, liderada por simpatizantes de direita e de esquerda, como a Semana de Arte Moderna

\footnotetext{
${ }^{4}$ Ver NETO (2013). Disponível em: http://www.revistas.uniube.br/index.php/anais/article/viewFile/752/1049 Acesso em 10/06/2016.
} 
(1922), a criação do Partido Comunista (1922), o Movimento Tenentista (1922). Ainda conforme as autoras, nesse contexto sócio-histórico, a democratização da escola se constitui como bandeira de luta, sendo empreendidas reformas educacionais em diferentes estados brasileiros: São Paulo (1920), conduzida por Sampaio Dória; em Minas Gerais (1927-1928), por Francisco Campos e Mário Casasanta; Rio de Janeiro, distrito federal (1928), por Fernando Azevedo; e Bahia (1928), conduzida por Anísio Teixeira.

Em Minas Gerais, a Reforma Francisco Campos, implementada pelo Regulamento do Ensino Primário (1927), complementada pelo Regulamento do Ensino Normal (1928) e pelos Programas do Ensino Primário (1928) orientou-se por princípios da Escola Nova. Conforme Maciel e Frade (2006), a Reforma educacional mineira era abrangente e teve por eixo norteador as inovações metodológicas, sendo que o governo mineiro empenhou esforços para levar adiante a proposta, não poupando esforços em difundir seu ideário e concretizá-lo no espaço das salas de aula.

Nesse movimento, ocorrem transformações na formação docente, sendo que em Montes Claros/MG, contexto investigado, esta assume caráter funcional e pragmático, embora alicerçada no conhecimento produzido pelas ciências, em especial a Psicologia. De um lado, o curso normal visa formar professores para a aplicação de princípios e metodologias defendidos pelo movimento da Escola Nova; de outro, espera-se que a profissão docente seja assumida como missão e sacerdócio, para a qual é necessária abnegação e amor às crianças e à escola.

Assim, a partir dos dados levantados, esse artigo objetiva discutir elementos constitutivos da história da profissão docente em Montes Claros/MG, nas décadas de 1920 e 1930, partindo da análise do processo de organização da primeira Escola Normal nesta cidade e estabelecendo um paralelo com a realidade mineira e nacional. $\mathrm{O}$ texto encontra-se estruturado em três partes: inicialmente situa-se o contexto de organização das Escolas Normais no Brasil Republicano e, em particular, na cidade de Montes Claros; em seguida discute-se o embate entre formação geral e formação profissional no âmbito das escolas normais, comparando o local e o contexto mais amplo; adiante aborda-se a questão da abnegação e da culpa como fundamentos para a formação e o exercício do magistério, também estabelecendo um paralelo entre a realidade montes-clarense e o cenário mais largo. Por fim, a título de conclusão, exploram-se os elementos que se apresentam como constitutivos da profissão docente no bojo da organização da Escola Normal de Montes Claros.

\section{Situando o Contexto: as Escolas Normais e a República}

No Brasil republicano as discussões sobre as escolas normais assumem centralidade dada à compreensão de que a educação impulsionaria a modernidade e o progresso. Ao discutir a educação na Primeira República, Jorge Nagle afirma haver uma preocupação com a escola normal, pois a formação de professores era a pedra angular para o êxito da nova escola primária, capaz de democratizar a cultura e contribuir para a superação das características semicoloniais ${ }^{5}$ da sociedade brasileira. (NAGLE, 2001).

Vilela (2000) analisa a importância da formação de professores nesse período, destacando o papel das instituições formadoras na renovação das práticas:

As escolas normais eram os locais "autorizados" para a difusão de um tipo de conhecimento normatizado que deveria caracterizar o "novo" professor primário, distinguindo-o dos seus antecessores, os "velhos" mestres-escolas, e alguns conteúdos foram se transformando num corpo de saberes característicos dessa formação (2000, p. 109 - grifos da autora)

\footnotetext{
${ }^{5}$ Para Reis (2007) a sociedade brasileira no início do século XX era considerada como semicolonial e semifeudal porque estaria sob o domínio do latifúndio e do imperialismo e resistente aos avanços da nação e das forças produtivas desejado pelo povo e pela burguesia. REIS, José Carlos. As Identidades do Brasil: De Varnhagen a FHC. 9.ed. Rio de Janeiro: Editora FGV, 2007.
} 
Contudo, conforme Tanuri (2000), o quadro social, político e econômico da Primeira República não favoreceu a difusão do ensino e a produção de novas idéias no campo educacional, apenas deu continuidade a movimentos e projetos educativos já em curso nas últimas décadas do período imperial. Como afirma Vilela (2000), na passagem da Monarquia para a República, a definição de um projeto de formação de professores somente encontrou ressonância na Escola Normal de São Paulo, sob a gestão de Caetano de Campos, que iniciou a reforma do ensino a partir de 1890. Ainda conforme a autora, o traço marcante da reforma não era o currículo enciclopédico e de forte conotação cientificista. O maior destaque é a concepção do que seja uma instituição formadora de professores:

Nada que lembre os "pardieiros" anteriores, prédios emprestados, móveis adaptados, pobreza de material didático. Para Caetano de Campos era necessário pensar grande e projetar no espaço do futuro aquela que seria uma verdadeira escola normal (2000, p. 118 - grifos da autora).

Mais ainda, em São Paulo, para além de um arrojado projeto arquitetônico, a prática pedagógica se constituiu como pedra angular da reforma, em que os alunos-mestres eram colocados em contato com o que havia de mais atualizado. Vilela ainda lembra que, no Rio de Janeiro, a primeira escola pública foi criada em 1880, abrindo suas portas no ano seguinte, com um currículo ambicioso, orientado pela lógica positivista de Augusto Comte e pela busca de maior definição acerca da formação de professores. Com a república, as Reformas de Benjamin Constant (1890 e 1892) visaram à instauração de um modelo arrojado de formação no âmbito da Escola Normal da Capital. No entanto, "a morte prematura de Benjamin Constant, os novos rumos da República e as críticas ao currículo pretensioso (e de difícil execução) da escola Normal acabaram por desfigurar os objetivos daquela experiência (2000, p. 117). Assim, apesar do intento, a capital da República não conseguiu renovar o seu projeto de formação docente, somente o fazendo nas décadas de 20 e 30 do século XX.

No estado de Minas Gerais também não ocorreram mudanças educacionais significativas com a República. A formação de professores já vinha passando por reformas no governo imperial - período em que se observa a progressiva legitimação da Escola Normal de Ouro Preto e a descentralização da formação de professores pela implantação de novas escolas normais na província mineira (GOUVÊA, 2002).

Excetuando São Paulo, que produziu ampla reforma do ensino normal e do ensino primário no final do século XIX, o advento da República não significou rompimento, mas continuidade dos processos já em curso no período imperial. No Brasil republicano, os grandes movimentos de reforma educacional somente tiveram lugar nas décadas de 1920-30, visando à reconstrução nacional pela educação e a conformação dos homens e da sociedade aos novos ideais de progresso e civilização. Na concepção de Nagle, na década de 1920, as escolas normais sofreram transformações mais profundas do que as escolas primárias. "A 'velha' escola normal já não atendia mais, com sua falta de conteúdo especial, às novas exigências propostas pela escolarização; as escolas normais existentes constituíam um curso de 'humanidades' de segunda classe" (NAGLE, 2001, pp. 281-282 - ênfases do autor).

O final da década de 1920 inaugurou um período de intensa discussão acerca do ensino, que define a escola normal como instância formadora de professores necessários ao projeto educativo pretendido. Na década de 1930, este projeto se consolidou por influência das idéias renovadoras, adotadas por Fernando de Azevedo, Anísio Teixeira e Lourenço Filho na reforma do ensino no Rio de Janeiro, então capital da república, e se disseminaram para outros Estados, influenciando seus projetos educativos. 
Como explicitado na seção anterior, Minas Gerais se enquadra nesse contexto de mudanças, colocando em curso a Reforma Francisco Campos (1927-1928), que propôs mudanças na estruturação do ensino normal e primário. Em Montes Claros, a história da profissão docente não se distancia dessas questões, desafios e mudanças. Apesar de marcada pela descontinuidade, entre fechamentos e reaberturas, dificuldades e glórias, a sua Escola Normal $^{6}$ inseriu-se no movimento de reforma educacional, sobretudo, nos últimos anos da década de 1920 e primeiros de 1930, em que viveu um período de intenso debate e renovação de práticas que foi importante para sua definição como instância formadora de professores para a região Norte Mineira. Por inserir-se no contexto de renovação proposto pela Reforma Francisco Campos, a Escola Normal de Montes Claros disseminou princípios defendidos pela Escola Nova, passando a fazer parte da tradição da cidade e do imaginário de sua população.

\section{Formação Docente: entre Cultura Geral e Formação Técnica}

No período entreguerras a proposta de reformar a sociedade pela reforma do homem se propagou mundialmente, a partir da Liga Internacional de Educação Nova, fundada em 1921, por ocasião do I Congresso Internacional de Educação Nova, realizado em Calais, por educadores que acreditavam na possibilidade de reformar o mundo desmoralizado através da escolarização. Segundo Carvalho, a Liga era composta por diferentes agrupamentos de educadores e, com o fortalecimento do Grupo Francês de Educação Nova (GFEN), passam a existir pelo menos duas grandes tendências orientadoras da ação pedagógica. A primeira, dominante nos debates, desde a fundação da Liga (1921) até o Congresso de Elsenor (1929), é representada por Beatriz Ensor e Ferrière. Este tendência se orientava pela "[...] ênfase mística nas potencialidades inatas e na energia espiritual da criança, pautando o programa escolanovista de renovação da escola". Já a segunda tendência, inicialmente representada pelas posições de Fauconnet, seguido pelas ideias de Pierón, Lanvengin e Wallon, caracterizava-se pelo debate em torno da "escola única" e do impacto internacional produzido pela experiência revolucionária de educação russa (CARVALHO, 2004, p. 153).

A escola única, comum e acessível a todos, igual em todos os seus graus, constituiu-se como importante discussão no âmbito da Escola Nova. A proposição assenta-se no princípio do direito de cada indivíduo a uma educação integral, capaz de promover o desenvolvimento de todos, de acordo com suas aptidões vitais, visando promover o rompimento com a desigualdade social.

Carvalho (2004) lembra que, no congresso de Nice (1932), cujo tema central foi a relação entre educação e sociedade, evidenciaram-se as divergências de orientação no interior do movimento da Escola Nova. "A oposição entre tendências místicas e racionalistas foi, na percepção dos participantes do congresso de Nice, uma das linhas divisórias que demarcou a diversidade de posições que se manifestaram no evento" (2004, p. 174). Nesse congresso, foram tecidas críticas aos princípios e fundamentos que regiam a Liga, colocando-se em questão a efetividade de uma campanha apoiada na psicologia, centrada apenas no respeito à natureza das

\footnotetext{
${ }^{6}$ Conforme Veloso (2009), a trajetória histórica da Escola Normal Official de Montes Claros pode ser compreendida em 3 fases. A primeira compreende o intervalo entre 1878 e 1905, período circunscrito entre o ano de sua criação como escola oficial, ainda no período imperial, e o de sua extinção por decreto do governo mineiro, em processo de contenção de despesas. A segunda fase delimita-se pelo período entre 1915 e 1938 , período de fundação da Escola Normal Norte Mineira, como escola livre e sua extinção como Escola Normal Oficial, novamente, por determinação do governo mineiro em função de corte de custos. Essa segunda fase inclui a desativação da escola livre no ano de 1918, sua reabertura em 1923, sua equiparação às escolas oficiais de Minas em 1925 e, por fim, o seu encampamento pelo poder público estadual em 1928, quando reassume o status de escola normal oficial. A terceira fase da escola tem início em 1953, ano em que a instituição foi reaberta como escola oficial, e se prolonga até o momento atual, em que funciona como escola regular de educação básica. Em todas essas fases, é intensa a luta de educadores montes-clarenses por superar as dificuldades garantir o funcionamento desta instituição formadora.
} 
crianças. Era necessário avançar, no sentido de redefinir o conceito de aptidão, não sendo possível falar em aptidão pura. Ao discutir a formação da criança, não se poderia apenas deixála crescer, mas que o seu desenvolvimento espontâneo fosse favorecido por um ambiente adequado (CARVALHO, 2004).

Em outras palavras, a discussão sobre a escola única coloca em cena as relações entre escola e sociedade. Para Carvalho (2004), ao se preocupar com a escola única e as questões conexas a essa temática, ou seja, a redefinição entre cultura geral e cultura profissional, o Grupo Francês de Educação Nova (GFEN) coloca foco na íntima relação entre o problema da educação e o problema da justiça social.

Carvalho lembra que, o modo como no livro Introdução ao Estudo da Escola Nova, Lourenço Filho traz a questão da escola única, foi criticado por Fauconnet, dado que ele tenha reduzido a campanha pela escola única na França. As críticas ainda se referem ao fato de que a escola única tenha sido colocada como um problema restrito "as velhas nações da Europa" em que havia "duas organizações de ensino oficial paralelas", fato que impunha a necessidade da escola única. "No Brasil, ao contrário, as escolas não distinguiam as crianças 'pelo seu nascimento, raça, cor, profissão dos pais, nacionalidade ou religião' e, por isso, como em todos os países da América, a questão da escola única era inexistente" (LOURENÇO FILHO, S/D, p. 23, citado por CARVALHO, 2004, p. 177).

Conforme Carvalho (2004), no contexto francês, o recurso à "iniciação" aparece articulado ao conceito de "cultura geral". Defende-se uma iniciação às diferentes formas de atividade humana, aos diferentes modos de expressão e ação, não apenas para determinar as aptidões individuais, mas também permitir uma ligação com os outros homens. Assim concebida, a cultura geral se constituía como aquilo que aproxima e une os homens, enquanto a profissão representa aquilo que separa. Neste contexto, a Rússia houvera implementado um projeto de educação que consistia em fazer do ofício, da profissão como ponto de partida da cultura, sendo a opção pela escola do trabalho considerada como uma reviravolta operada no campo educacional. "A magnitude do investimento educacional soviético exercia esse tipo de atração: ele punha à prova o poder da educação em processos de transformação social” (2004, p. 176).

A autora acredita que os excepcionais aportes da pedagogia soviética tenham sido captados por Fernando de Azevedo, "intelectual informadíssimo", que, impactado pelas transformações culturais do seu tempo, tenha incorporado tais aportes na implementação da reforma que implementou no Rio de Janeiro. A Reforma no Distrito Federal, proposta por Azevedo, objetivou implantar a "escola única" como "escola do trabalho", redefinindo os programas da escola primária e tomando medidas de reformulação e integração do ensino técnico-profissional (CARVALHO, 2004). Conforme Vidal (2001), nos últimos anos da década de 1920 e primeiros da década subsequente, são perceptíveis as influências das propostas disseminadas pela Liga e, no bojo das reformas educacionais e da consolidação das escolas normais, o ensino propedêutico e o profissional foram tema de debate e divergências. Essa tensão entre cultura geral e ensino técnico profissional esteve presente nas discussões que orientaram a reforma da Escola Normal do Rio de Janeiro. Iniciada em 1928, por Fernando de Azevedo, a reforma teve continuidade com Anísio Teixeira, e posteriormente Lourenço Filho. Segundo Diana Vidal, nessa e em outras questões, as concepções dos reformistas conflitavam. Mas, entre debates e ideias conflitantes, o consenso se apresentava em relação à necessidade de inovar o ensino. Azevedo compreendia a cultura geral como elemento importante na formação das professoras, enquanto que Teixeira conferia primazia à prática profissional. $\mathrm{O}$ trabalho de Fernando Azevedo possibilitou a arrancada inicial para a renovação de idéias e práticas; enquanto que Anísio Teixeira possibilitou a conformação de uma nova prática de formação docente; cabendo a Lourenço Filho a consolidação dessa prática (VIDAL, 2001). 
Fernando Azevedo, Anísio Teixeira e Lourenço Filho exerceram papel importante na constituição de novas práticas educativas no Rio de Janeiro, e também contribuíram para a disseminação de princípios da Escola Nova, exercendo influência na definição de projetos educativos em diferentes Estados da federação. Minas Gerais não escapa a essa influência, que pode ser percebida no seu projeto de reforma.

Na análise da política educacional mineira pós-30, Peixoto (2003) afirma que a adoção dos princípios da Escola Nova apresentava saídas que atendiam às expectativas das classes emergentes mineiras, sem colocar em risco a estrutura de poder. Isto porque, permitia conferir uma aparência de renovação e mudança, sem verdadeiramente modificar as bases de organização da escola ou democratizar o seu acesso às camadas populares. Apesar de justificadas por dificuldades econômicas, as medidas contenedoras adotadas pelo governo tinham raízes mais profundas do que as alegadas, indicando mudanças no pensamento e na ação política. Assim, a política educacional mineira revela as tensões entre Estado e Igreja e as soluções de compromisso encontradas. Ou seja, não havia real interesse em democratizar o acesso à escola. A oligarquia mineira se opunha à ampliação das escolas oficiais, por temer a perda de poder político pela perda de controle sobre as massas esclarecidas. Por sua vez, com a proposta de expansão da rede pública de ensino - que os reformistas pretendiam leigo, obrigatório e gratuito - a Igreja passa a temer a perda de influência sobre a sociedade, pelo risco de descristianização da população (PEIXOTO, 2003).

Em Minas Gerais, nas primeiras décadas do século XX, discursos e publicações oficiais afirmam a importância do professor nas reformas, destacam a qualidade do ensino, apontam os avanços da legislação estadual, citam dados relativos à eficiência das ações desenvolvidas. Contudo, para Peixoto:

nos termos em que é colocado, esse relevo à eficiência serviu apenas para ocultar e justificar a pobreza a que foi reduzida a educação nesse período e o importante papel que ele exerce no sentido de manter e legitimar os mecanismos discriminatórios vigentes na sociedade (2003, p. 242).

Para a autora, o retrato da escola mineira, no pós-30, indica que ela era “(...) diferenciada, moralista, cientificista, autoritária em suas formas de atuação e extremamente hierarquizada em seu funcionamento" (2003, p.188).

Montes Claros se enquadra nesse contexto e reflete as medidas adotadas pelo governo mineiro, no que se refere à adoção dos métodos ativos, o controle do trabalho do professor, a valorização da atividade técnica e a defesa dos valores e da ética cristã na educação das novas gerações. De forma similar aos processos que tiveram curso no Rio de Janeiro, em Montes Claros, o debate entre o ensino propedêutico (de formação geral) e o ensino profissional (de formação técnica, para o trabalho) também se fez presente. Revelando o teor de discussões propostas no âmbito da Escola Normal Oficial de Montes Claros, em matéria publicada no mês de maio de 1934, uma aluna do Curso de Aplicação defende que o curso normal deveria ter base técnica e profissional, argumentando que as matérias de natureza propedêutica, nesse nível de ensino, deveriam servir de fundamento para a atividade técnica. Ao abordar as deficiências do ensino, indica que o curso normal não estava sendo bem compreendido, nem convenientemente executado por alguns professores da Escola Normal Oficial de Montes Claros e de outros institutos congêneres do Estado, por focalizarem sua atenção no ensino propedêutico. Em suas palavras: 
Ordinariamente, é o ensino propedêutico, se bem que lacunoso, o objecto da preocupação dessas escolas.

Será que os seus elementos não vêem a larga modificação que ao ensino normal determinaram as profundas investigações relativas ao ensino primário? O facto é que, embora muitos não admitam, deve existir entre o ensino primário e o normal absoluta correlação.

O ensino normal é, antes de tudo, ensino profissional; elle visa à acquisição de technicas e igual objectivo devem visar as matérias propedêuticas, matérias que servem para dar noções geraes necessárias à vida. Escola Normal, pois, deve ser, antes de tudo, escola technica. Assim sendo, não é apenas a methodologia que se deve relacionar com o ensino profissional, mas todas as outras que constituem o currículo normal (SANTOS, 26 de maio de 1934, p.01).

Ao discutir as necessárias relações entre ensino normal e primário, a argumentação da aluna se encaminha para a profissionalização e a experiência prática. Afinal, o curso de formação de professores deveria ser técnico e se constituir pela imediata aplicação de métodos de ensino nas classes primárias. Além de tecer críticas à organização do ensino, cujas matérias propedêuticas não serviam de fundamento à atividade técnica profissional, a aluna também critica os métodos de ensino utilizados pelos professores formadores, que não modernizaram suas práticas pela adoção de concepções da Escola Ativa e ainda se inspiravam nas ultrapassadas metodologias da escola verbalista de outrora.

No ensino normal, apezar dos brados da pedagogia moderna que o orienta, ainda se vê e não raro, o systema, o lamentável systema das aulasexposição, aulas monologo. As licções não devem constituir monólogos ou simples conferencia: - o professor deve appelar para a collaboração dos alumnos, para comentários e leituras úteis e ter em vista, principalmente, as experiências a realisar. Não se consideram pois, como dadas, as aulasexpostas, monologadas e ditadas (SANTOS, 26 de maio de 1934, p.01).

Percebe-se no discurso da aluna uma adesão às idéias de Anísio Teixeira, que compreendia a formação dos professores como atividade técnica, focada nas disciplinas profissionalizantes, no exercício docente e na experiência prática. Percebe-se, também, uma adesão aos princípios educativos que orientavam a política educacional mineira, que focalizava a reforma do ensino na reforma dos métodos.

O ensino normal não é um simples curso de cultura propedêutica, mas, antes de tudo, cultura technica e profissional de applicação immediata nas classes primarias.

Proceder contrariamente a essa, não apenas regra, mas necessidade, que implica a nossa vida pratica futura, é tirar todo o fulgor do nosso enthusiasmo afeito às possíveis conquistas no campo profissional; é habituar-nos, a nós alumnas, a uma vagabundagem mental, a um tédio e desamor pela Escola, a uma aversão pela matéria e, consequentemente, pelo seu responsável; é tolher nossa atividade e transformar-nos em seres passivos, à margem da lucta pela vida, incapazes de iniciativa e acção próprias, é desintegração perfeita de nossa vida mental e de nossa personalidade às realidades da vida e à acção efficiente, fóra das quaes nada se pode fazer em beneficio da civilização! (SANTOS, 26 de maio de 1934, p.01). 
Ao afirmar as ligações do ensino normal com a escola primária e a necessidade de uma cultura técnica e profissional na formação dos professores, a aluna da Escola Normal Official de Montes Claros não apenas se posiciona contrariamente à ênfase propedêutica, mas, sobretudo, faz a defesa da renovação dos métodos de ensino. Isso porque, em sua concepção, os conteúdos e os processos formadores utilizados nas escolas normais exerceriam dupla influência nas professoras em formação. De um lado, a vivência de modernas metodologias possibilitaria a aquisição de técnicas aplicáveis ao ensino primário; e de outro, favoreceria a conformação de um conjunto de disposições capazes de produzir o amor à escola, à disciplina, ao trabalho, entusiasmo e gosto pelo magistério.

Tais afirmações e preocupações da aluna, voltadas para o aprender a fazer, para a aquisição de um saber técnico e pragmático, refletem as mudanças ocorridas na formação dos professores mineiros, e encontra-se com análises realizadas por Ana Maria Casasanta Peixoto, que sinaliza a ambiguidade dos discursos sobre e para o professor. Inicialmente, no governo Antônio Carlos Ribeiro de Andrada (1926-1930), ocorre a ampliação e a melhoria de escolas e o discurso girava em torno da adoção dos métodos ativos. Já no governo pós-30, a política educacional se define pela contenção, mantendo-se o ideário escolanovista, que assume o sentido da reforma educacional. Contudo, nos discursos dirigidos aos professores, não há uma preocupação em explicitar os princípios orientadores da renovação — tratava-se de garantir a sua aplicação (PEIXOTO, 2003).

Peixoto lembra que essa abordagem utilitarista da política educacional mineira pôde ser percebida nas publicações da Revista do Ensino/MG que, como porta-voz do governo junto ao professorado, gradualmente vai assumindo essa nova orientação. Assim, questões polêmicas passam a ocupar espaço reduzido, na medida em que cresce o número de matérias destinadas a evidenciar a eficácia dos métodos na abordagem dos problemas educacionais.

Em 1934 a Revista solicita o envio de relatos de experiências e atividades desenvolvidas pelos professores, passando a publicá-los como uma espécie de modelo de prática docente a ser disseminado por todas as escolas mineiras. Na medida em que se atêm à descrição de atividades, omitindo aspectos importantes, como a definição de critérios que orientam sua escolha, e não fazem uma avaliação mais profunda do seu desenvolvimento e significado como método de aprendizagem, as publicações da Revista assumem um caráter mecanicista.

Subjacente a essa forma de apresentação há um viés de ordem epistemológica, que se traduz pela crença na eficiência de uma ação distanciada da reflexão. Isto, na prática, confere aos relatos o caráter de "receitas", que o professor pode e deve aplicar (PEIXOTO, 2003, p. 174).

Ainda segundo a autora, não apenas as publicações da Revista do Ensino, mas também as do jornal Minas Gerais, constituem-se como importante recurso de divulgação do projeto de escola que se quer propagar no Estado; refletem as mudanças processadas na formação dos professores; indicam o papel docente na organização do trabalho pedagógico; e servem para quebrar a resistência de professores conservadores, levando-os à adesão aos novos métodos (PEIXOTO, 2003).

Enfim, a reforma de métodos, que enfatiza a formação técnica do professor e se distancia da reflexão teórica, não limita suas influências aos processos de ensinar. Essa abordagem produz mudanças na forma como passa a ser compreendida a profissão docente - que desloca o papel do professor, exige-lhe abnegação e sacrifício e lhe atribui culpa pelo fracasso do aluno. 


\section{3- Profissão Docente: o Professor entre Abnegação e Culpa}

Como resultado das concepções educativas em circulação, na década de 1930, ocorre um deslocamento nas discussões relativas ao espaço destinado ao professor em sala de aula não mais ocupa lugar central na tarefa educativa e a sua qualificação passa a ser discutida e questionada. De figura central, o professor passa a ser compreendido como orientador da aprendizagem; de detentor do conhecimento, passa a ser desqualificado e apontado como obstáculo para a implementação das mudanças necessárias. A crença na auto-educação produz a idéia de que o próprio indivíduo educaria a si mesmo. E, por esse viés, muitos passam a compreender que a atuação do professor poderia ser prejudicial ao desenvolvimento da criança. Nas palavras do assistente técnico do ensino, o professor José Raymundo Netto ${ }^{7}$ em publicação da Revista do Ensino/MG, "a nova pedagogia chegou mesmo a promulgar que, na obra educativa, o professor é um mal necessário" (janeiro de 1930, p. 71).

Contudo, esse deslocamento não significou o esvaziamento da função docente. Mesmo considerando que as novas concepções colocam o aluno como centro do processo de aprendizagem, o próprio José Raymundo Netto não desqualifica o trabalho docente.

Só muito ao fundo do scenario apparece-nos a personalidade do professor, deslocado pelas novas correntes pedagógicas, para um plano secundário: - de senhor absoluto que era, único cérebro a pensar e a dizer, passou, na escola, a ser o amigo em quem se confia, o orientador a quem se consulta, o guia, cujo auxilio é sempre seguro e valioso (janeiro de 1930, p. 71).

Em suas representações, na atividade escolar, o lugar do professor deixa de ser o centro, mas a sua função é importante, sendo necessário investir na sua formação. No exercício de sua função como assistente técnico do ensino, "em suas peregrinações" pelos mais afastados "rincões do Estado", José Raymundo Netto pudera constatar que, “[...] o mais grave e relevante problema da Reforma do Ensino está sendo, na hora que passa, a formação do professorado mineiro, sua orientação nos caminhos indicados pelas sábias disposições de nossos nos regulamentos". Afinal, se:

não pode haver, de facto, bons methodos sem bons professores; somos, pois, forçados a concentrar em torno do educador nossas mais serias preocupações, já que a solução de seus problemas depende o êxito completo da grande campanha innovadora a que nos vimos dedicando (janeiro de 1930, p. 72).

\footnotetext{
${ }^{7}$ O ilustre educador José Raymundo Netto (1897- 19??) nasceu em Carangola/MG, foi professor de Psicologia, Metodologia e Prática Profissional e de diretor da Escola Normal Official de Montes Claros entre 1935 e 22 de janeiro de 1938, data em que a escola foi suprimida por Decreto Lei n. 63, do governo mineiro. Após o fechamento da Escola Normal, Raymundo Neto exerceu a função de professor de Psicologia do Colégio Imaculada Conceição de Montes Claros. Na época em que publicou artigos na Revista do Ensino, o professor era Assistente Técnico do Ensino no governo de Minas Gerais. De acordo com Nelson Viana (2011), Raymundo Netto fez o curso primário em Januária e o secundário em Paracatu. Além das atividades em Montes Claros, exerceu a advocacia civil e criminal em Januária, onde foi professor da Escola Noturna. Fundou, dirigiu e foi professor de Português, Geografia, História e Ciências no Ginásio de Três Corações, Sul de Minas, de 1931 a 1933. Também foi Diretor do Grupo Escolar de Espinosa (Disponível em: http://montesclaros.com/n/mural.asp?pg=578. Acesso em $11 \mathrm{de}$ julho de 2016. Publicação n $5^{\circ}$ 69258, em 11/10/2011, 07:26:39).
} 
Por essa visão, é possível compreender os deslocamentos ocorridos na formação dos professores, que sinalizam para a competência técnica e a aplicação dos novos métodos de ensino. Mesmo não sendo o centro da atividade escolar, o professor era o eixo da mudança. Não exercia papel central na sala de aula, mas sua atuação era central para o êxito do programa de reforma. Cabia-lhe a responsabilidade pela inovação, pela adoção dos modernos métodos de ensino e a orientação da atividade do aluno. Nesse sentido, o investimento na sua formação assume contornos diferenciados - os professores deveriam ser preparados para a implementação da reforma, assumindo o trabalho como missão, ao qual se dedicariam e pelo qual fariam sacrifícios.

Pesquisa realizada por Ana Maria Casasanta Peixoto indica que, na década de 1930, o professor ocupa lugar central no projeto de reforma, sendo-lhe atribuída uma grande responsabilidade sobre o fracasso escolar. Segundo a autora, o discurso acerca do professor era carregado de ambiguidades e dividido em torno de duas abordagens. De um lado, o amor e o respeito à criança, a adesão aos princípios escolanovistas e a aplicação de novas metodologias, colocavam a formação teórica em segundo plano. De outro lado, a difusão de um humanismo espiritualista, pelo qual se esperava o exercício do magistério como missão e sacerdócio. Esperava-se, ainda, que o magistério fosse capaz de formar o cidadão, pela via do nacionalismo e do amor à pátria (PEIXOTO, 2003).

Conforme Peixoto (2003), no período de governo do interventor Benedito Valadares (1933-1937), as representações disseminadas indicam que a importância do professor não deveria ser medida pelo seu salário, pois a retribuição à importância do seu trabalho não se aquilatava pela via material. A recompensa do professor era o reconhecimento social do trabalho e a satisfação do dever cumprido. O discurso sobre e para o professor já não se preocupava em estimular o desejo de aprender, mas explorar o caráter missionário da sua atuação. Dessa forma, embora o governo afirmasse sua preocupação com um professorado eficiente e reiterasse a intenção em disponibilizar recursos para seu contínuo aperfeiçoamento, na prática, o programa concebido com essa finalidade não visava dotar o professor de autonomia no campo intelectual. Na prática, esse esvaziamento do plano intelectual impedia que o professor pensasse o seu fazer, por não possuir conhecimento que lhe permitisse analisar teoricamente a sua ação: "O que explica que o discurso sobre/para o professor exalte as virtudes de caráter e dele já não se exija ciência (pensamento), mas abnegação e sacrifício no desenvolvimento de tarefas (execução)" (PEIXOTO, 2003, p. 212).

Alias, essa defesa da abnegação e do sacrifício não era um discurso novo, mas foi atualizado no pós-30, visando a conformação dos professores às condições de trabalho daquele momento. Em discurso proferido pela oradora das formandas de 1926, da Escola Normal Oficial de Montes Claros, a aluna Geraldina Alves fala da importância do diploma, fruto do investimento pessoal, mas, sobretudo, destaca o esforço de seus professores, que se sacrificaram e superaram dificuldades para transmitir-lhes o seu saber. Esse espírito de abnegação e altruísmo conduzia à percepção do magistério como missão e sacerdócio e, por esse motivo o entusiasmo a mover a ação do professor era sagrado:

Amar a creança, estudal-a, entender-lhe a psycologia, orientar-lhe de forma carinhosa e clarividente a forma da personalidade - eis deveres inherentes ao nosso cargo altruísta de finalidades vastas. Quando encontramos uma creança emancipada de idéias pequeninas, liberal em todos os assumptos, tolerante e bôa, que devemos fazer como educadoras?

Devemos, incessantemente no enthusiasmo sagrado do nosso luminoso sacerdócio, debruçar-mos sobre o ser desabrochante, collocando sobre nossa solicitude, como verdadeiras artífices, plasmar-lhe o crescimento physico e intellectual e dar-lhe nobreza moral (ALVES, 12 de fevereiro de 1927, p. 04). 
No desempenho desse sagrado sacerdócio, o amor à educação e a abnegação eram qualidades fundamentais, e o professor se encheria de alegria em contemplar os resultados do seu trabalho estampados na criança, que se tornaria útil, emancipada e forte, e nos espíritos juvenis que se aperfeiçoariam pela cultura. Assim, na obra da instrução e da regeneração social, o professor se sentiria compensado por todo o sacrifício e cansaço.

Quantos dissabores, que incalculável acervo de desapontamento e que ânsias adveem quando há palpitante e verdadeiro amor à causa da educação infantil.

Mas quando as aspirações do bem e da sabedoria desabrocharem e florescerem nos tenros coraçõezinhos que toda a vigilância cerca; quando os juvenis espíritos se forem aperfeiçoando pela cultura sadia e indispensável, e da creança illetrada surgir o individuo culto, útil, emancipado, forte - a alegria, galardão supremo, secundará a alma do professor abnegado e compensará sobejamente, a fadiga, quiçá o desanimo que o assaltara, às vezes, no decorrer da obra da instrucção, da regeneração!... E porque também não havemos de sentir um dia a invasão desse mesmo orgulho aos nossos corações?!... (ALVES, 12 de fevereiro de 1927, p. 04).

É interessante destacar a ambivalência do discurso sobre e para o professor - ora elogiado e valorizado, ora responsabilizado pelo fracasso dos alunos. Em Montes Claros, se em 1927 o discurso era de enaltecimento do altruísmo e da abnegação dos professores, em 1934, consoante com as concepções da época, o tom de acusação se mostra presente nas palavras de outra aluna da Escola Normal Oficial de Montes Claros. Ao discutir os problemas do ensino a aluna culpabiliza os professores, apontando-lhe o descaso, a falta de profissionalismo e o desinteresse pelo magistério.

Poucos, sinão raros, a elle [trabalho docente] se atiram com verdadeiro gosto e enthusiamo, e por moveis intrínsecos relacionados com o alto ideal da Educação.

Falta vocação, de aptidão didática, afan do dinheiro, ganha-pão = é o que ao primeiro golpe de vista se observa (SANTOS, 26 de maio de 1934, p. 01).

E mais, em suas concepções, as dificuldades de se implantar as modificações e renovar as práticas educativas se localizavam nas falhas dos professores. Em suas palavras:

Francisco Campos, querendo modificar o ensino primário, reconheceu a necessidade primacial de se modificar o ensino normal attendendo a que os defeitos daquelle residem no professor. Está nas mãos deste o desenvolvimento ou o estacionamento do alumno, muito embora alguns de desenvolvam com o professor, sem o professor e maugrado o professor (SANTOS, 26 de maio de 1934, p. 01).

Essa atribuição de culpa aos professores é retomada pelo professor José Raymundo Netto, então diretor da Escola Normal Official de Montes Claros. Ao discutir a reforma da educação em Minas Gerais, tece elogios às iniciativas do governo e indica que os resultados ainda não eram observáveis, porque "o carrascal da rotina era espesso" (RAYMUNDO NETTO, 19 de maio de 1934, p. 01) e, para efetivar as mudanças, era necessária perseverança, 
paciência e estímulo aos desbravadores. Em suas concepções, uma das tarefas mais árduas desse movimento renovador coube aos Assistentes Técnicos, que deveriam romper com a apatia dos professores. Segundo o então diretor da Escola Normal Official de Montes Claros:

Mudar a mentalidade da grande maioria do professorado, desperta-lo da semi-letargia a que fora arrastado pela estagnação de longos tempos, levando-o a perceber que o ensino é vida, é desenvolvimento, e que o scenario da Educação é bem vasto para que estejamos a marcar passos, presas do habito, ou victimas de anchronicos systemas educativos (itálico no original) (RAYMUNDO NETTO, 19 de maio de 1934, p.01)

Nesse mesmo sentido, no ano anterior (1933), ao discursar para as formandas da Escola Normal de Juiz de Fora, Noraldino Lima ${ }^{8}$ já houvera destacado a rotina como um dos problemas a serem tratados pelas escolas mineiras. Em suas palavras, "a sedimentação da rotina precisa ser, deve ser, há de ser, entre nós, desfeita, pulverizada, destruída até os seus mais remotos fundamentos" (LIMA, 1 de janeiro de 1933, p. 10). E esse esfacelamento da rotina cabia aos professores, mas o despertar da letargia cabia aos técnicos.

Por esses discursos é possível perceber que a inovação das práticas educativas dependia da atuação docente. Contudo, os professores eram desqualificados e considerados inaptos para empreenderam a reforma necessária, dada à preguiça, à rotinização do seu trabalho, à falta de estudo, à acomodação.

Nessa direção, que sinaliza para a importância dos professores, como também para os problemas advindos de sua atuação, José Raymundo Netto (19 de maio de 1934, p.01) publica matéria no jornal Gazeta do Norte, em que apresenta uma síntese de 200 trabalhos, escritos por professores de vários estabelecimentos de ensino por ele inspecionados, quando ainda exercia a função de Assistente Técnico do Ensino. Nesses trabalhos os professores haviam elencado uma série de problemas, em resposta às seguintes perguntas: “a) Quais são, nesta localidade, os maiores obstáculos à efficiencia do Ensino?; b) De que recursos se pode valer a escola para combater esses males?”.

Dentre os vinte problemas elencados, apenas um refere-se à atuação dos Assistentes Técnicos; cinco relacionam-se às condições de funcionamento dos Grupos Escolares; outros seis associam-se à precariedade da condição dos alunos. Contudo, oito destes elementos dificultadores, dizem respeito aos professores, e estão relacionados a diversos aspectos de sua atuação profissional, como a falta de entrosamento e cooperação, de coleguismo e solidariedade; a incapacidade intelectual e cultural; a falta de preparo pedagógico e a utilização de metodologias de ensino inadequadas; não deixando de apontar a sua condição de miséria e os reduzidos salários, que geram problemas de saúde, constantes licenças e dificuldades para serem substituídos.

\footnotetext{
${ }^{8}$ Noraldino Lima nasceu em São Sebastião do Paraíso (MG) no dia 12 de janeiro de 1885 . Fez seus estudos básicos no Colégio Espírito Santo, na cidade mineira de Monte Santo. Na cidade de Juiz de Fora /MG, em dezembro de 1908, concluiu o curso secundário e, em abril de 1910, diplomou-se em farmácia. Em Belo Horizonte, em dezembro de 1914, bacharelou-se pela Faculdade de Direito. Iniciou sua vida profissional no ano de 1910, em Belo Horizonte, onde foi nomeado escrevente da prefeitura municipal, ocupando, posteriormente, diferentes ocupações no governo estadual. Em 1919, assumiu a suplência de deputado estadual para a legislatura que se estenderia até 1922, período em que assumiu novo mandato de deputado estadual, em substituição a Francisco Campos. A convite do presidente de Minas Gerais, Raul Soares (1922-1924), Noraldino Lima tornou-se diretor da Imprensa Oficial e redator-chefe do Minas Gerais, diário oficial do estado, assumindo, posteriormente, outras atribuições no governo mineiro, dentre os quais a de diretor da Instrução Pública do estado (1927) e dirigente da Secretaria de Educação e Saúde Pública de Minas, entre setembro de 1930 e fevereiro de 1935). Posteriormente, Noraldino Lima ocupou diferentes funções e cargos públicos (CALICCHIO, S/D).
} 
Por essas respostas é possível perceber que, não era apenas o Governo Mineiro e o serviço de Assistência Técnica que focalizavam nos professores a maior parcela de responsabilidade quanto ao sucesso ou fracasso na implantação da reforma. Os próprios professores assumiam essa responsabilidade e indicavam a necessidade de mudança na sua atuação e formação, visando à atualização profissional e uma maior integração entre si e com os pais dos alunos. Eram complexos os problemas identificados pelos professores.

É possível perceber, também, que as dificuldades e obstáculos apontados pelos professores não se resolveriam apenas com a reforma dos métodos e processos de ensino, como propunha o governo mineiro. Até mesmo essa mudança no interior da escola demandava por investimentos financeiros, de forma a se viabilizar o atendimento aos alunos pobres e a adequação dos livros escolares de leitura; rever a formação e o preparo dos professores e melhorar suas condições de trabalho.

\section{Considerações Finais}

A organização da primeira Escola Normal em Montes Claros reflete uma característica presente nessas instituições no âmbito nacional, qual seja, a descontinuidade na oferta de formação docente pelo estado,- - descontinuidade percebida por um frequente processo de fechamento e reabertura dessas escolas.

Nesse quadro, ao se analisar a organização da primeira Escola Normal em Montes Claros, para além desta descontinuidade, outras questões se destacam quando busca-se identificar elementos que fazem parte da profissão docente no município. Nota-se que o papel conferido às escolas normais impacta a formação e o exercício do magistério, em um contexto que a profissão docente é marcada, tanto no âmbito local, quanto no contexto mineiro e nacional, pelo embate entre formação técnica e cultura geral, e pelas ideias escolanovistas de mudança e de renovação dos métodos de ensino.

Ressalta-se que, na década de 1930, a política educacional mineira se distingue das opções e orientações assumidas por outros estados brasileiros - ao adotar estratégias de contenção da oferta do ensino normal, o Estado de Minas Gerais procura justificar sua posição a partir da adoção de uma política de reforma das metodologias de ensino, acusando os professores de desinteresse e apatia, responsabilizando-os pelo fracasso escolar.

O exame da realidade indica que Montes Claros não foge ao quadro geral do Estado de Minas, refletindo sua adesão ao programa de reforma educacional proposto para as escolas normais e para o ensino primário. Nesse sentido, faz a defesa do magistério como missão e sacerdócio e do ensino normal como atividade técnica. No entanto, no bojo da Escola Nova, a renovação de metodologias assume grande centralidade, mas não se desconsidera a necessidade de uma ampla cultura geral, que permitiria aos professores a transformação de suas práticas, bem como a assunção de um posicionamento reflexivo diante dos problemas e dificuldades encontradas no exercício docente.

No contexto investigado, ocorreram transformações na formação docente. Observa-se que a Escola Normal de Montes Claros assume um lugar de destaque na produção de representações sobre e para os professores, disseminando posicionamentos que visavam orientar ações. De um lado, o curso normal visava qualificar os professores para a aplicação de princípios e metodologias do movimento da Escola Nova; de outro, esperava-se que a profissão docente fosse assumida como missão e sacerdócio, para a qual seriam necessárias atitudes de sacrifício, abnegação e amor às crianças e à escola. 


\section{Referências}

CARVALHO, Marta Maria Chagas de. O Manifesto e a Liga Internacional de Educação Nova. In. XAVIER, Maria do Carmo (org). Manisfesto dos pioneiros da educação: um legado educacional em debate. Rio de Janeiro: editora da FGV, 2004. p. 147-182.

CHARTIER, Roger. História Cultural: entre práticas e representações. Trad. Maria Manuela Galhardo. Rio de Janeiro: Berthand do Brasil, 1990.

CALICCHIO, Vera. Verbete Noraldino Lima. CPDOC | FGV - Centro de Pesquisa e Documentação de História Contemporânea do Brasil. Disponível em: http://www.fgv.br/cpdoc/acervo/dicionarios/verbete-biografico/lima-noraldino Acesso em 10 de agosto de 2016.

DE LORENZO, Helena Carvalho; COSTA, Wilma Peres da (orgs.). A década de 20 e as origens do Brasil moderno. São Paulo: Editora da UNESP. p.159-184.

FRADE, Isabel Cristina Alves da Silva e MACIEL, Francisca Isabel Pereira. (2006). O Livro de Lili em Minas Gerais: hegemonia didática e suas influências. In.: FRADE, Isabel Cristina Alves da Silva e MACIEL, Francisca Isabel Pereira. (org). História da alfabetização: produção, difusão e circulação de livros (MG/RS/MT - Séc. XIX e XX). Belo Horizonte: UFMG/FAE. p. 95-116

MONARCHA, Carlos. Escola Normal da Praça: o lado noturno das luzes. Campinas-SP: Editora da Unicamp, 1999.

NAGLE, Jorge. Educação e sociedade na primeira república. Rio de Janeiro: DP e A, 2001.

GONÇALVES NETO, Wenceslau. Escola Normal de Montes Claros: controle e disciplina na preparação de professores primários em Minas Gerais (1888-1903). Disponível: http://www.revistas.uniube.br/index.php/anais/article/viewFile/752/1049

Acesso em 10/06/2016.

PEIXOTO, Ana Maria Casasanta. Educação e Estado Novo em Minas Gerais. Bragança Paulista/SP: EDUSF, 2003.

REIS, José Carlos. As Identidades do Brasil: De Varnhagen a FHC. 9.ed. Rio de Janeiro: Editora FGV, 2007.

TANURI, Leonor Maria. História da formação de professores. Revista Brasileira de Educação. Anped. Mai/jun/jul/ago. 2000, n. 14, p.61-88.

VELOSO, Geisa Magela. Imprensa e Escola Normal: representações de progresso e civilização na produção de um imaginário social - 1918-1938. Revista Brasileira de Educação. v. 14 n. 42 set./dez. 2009. Pp 488-603. Disponível em:

http://www.scielo.br/pdf/rbedu/v14n42/v14n42a07.pdf Acesso em: 11 de agosto de 2016.

VIDAL, Diana Gonçalves. O exercício disciplinado do olhar: livros, leituras e práticas de formação docente no Instituto de Educação do Distrito Federal (1932-1937). Bragança Paulista: Editora da Universidade de São Francisco, 2001. 
VILELA, Heloisa de O. O mestre-escola e a professora. In: LOPES, Eliane Marta Teixeira, FARIA FILHO, Luciano Mendes, VEIGA, Cyntia Greive (org.). 500 anos de educação no Brasil. 2. ed. Belo Horizonte, Autêntica. 2000. p.95-134.

VEIGA, Ilma Passos Alencastro (Org). Caminhos da profissionalização do magistério. 2.ed. Campinas-SP: Papirus, 2001.

\section{Fontes Documentais}

ALVES, Geraldina. A Festa das Normalistas. Discurso da alumna Geraldina Alves. Gazeta do Norte, Ano IX, no 508, 12 de fevereiro de 1927. (Acervo do CPDOC - Centro de Pesquisa e Documentação da Unimontes - Montes Claros).

LIMA, Noraldino. O momento educacional em Minas - Discurso do paraninfo às diplomandas da Escola Normal de Juiz de Fora. Revista do Ensino: órgão oficial da Inspetoria Geral da Instrução.

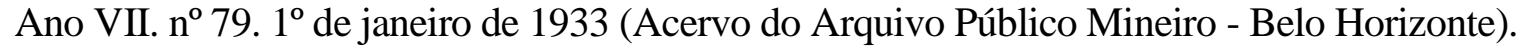

RAYMUNDO NETTO, José. O espírito associativo do professorado mineiro. Revista do Ensino: órgão oficial da Inspetoria Geral. Ano V. n 41. jan.1930 (Acervo do Arquivo Público Mineiro - Belo Horizonte).

RAYMUNDO NETTO, José. Problemas do Ensino em Minas. Gazeta do Norte. Ano XVI. n ${ }^{\circ}$ 914. 19 de maio de 1934 .(Acervo do CPDOC - Centro de Pesquisa e Documentação da Unimontes - Montes Claros).

SANTOS, Helena Sousa. Ensino Normal. Gazeta do Norte. Ano XVI. no 915. 26 de maio de 1934. (Acervo do CPDOC - Centro de Pesquisa e Documentação da Unimontes - Montes Claros). 